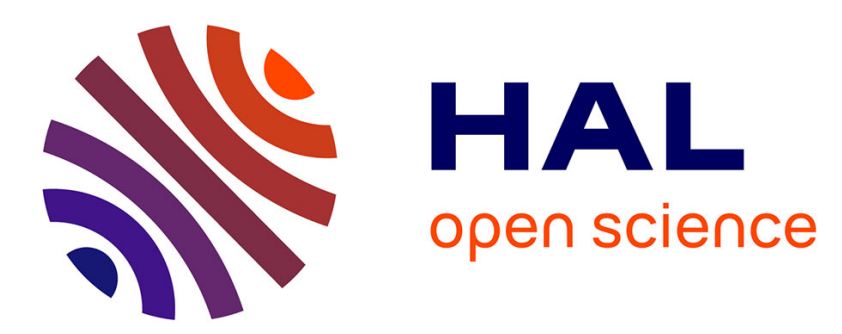

\title{
A biodegradation study of poly(3-hydroxybutyrate-co-3- hydroxyvalerate)/organoclay nanocomposites in various environmental conditions
}

Kahina Iggui, Nicolas Le Moigne, Mustapha Kaci, Simon Cambe, Jean-Regis Degorce-Dumas, Anne Bergeret

\section{To cite this version:}

Kahina Iggui, Nicolas Le Moigne, Mustapha Kaci, Simon Cambe, Jean-Regis Degorce-Dumas, et al.. A biodegradation study of poly(3-hydroxybutyrate-co-3-hydroxyvalerate)/organoclay nanocomposites in various environmental conditions. Polymer Degradation and Stability, 2015, 119, pp.77-86. 10.1016/j.polymdegradstab.2015.05.002 . hal-02914193

\section{HAL Id: hal-02914193 \\ https://hal.science/hal-02914193}

Submitted on 25 Jan 2021

HAL is a multi-disciplinary open access archive for the deposit and dissemination of scientific research documents, whether they are published or not. The documents may come from teaching and research institutions in France or abroad, or from public or private research centers.
L'archive ouverte pluridisciplinaire HAL, est destinée au dépôt et à la diffusion de documents scientifiques de niveau recherche, publiés ou non, émanant des établissements d'enseignement et de recherche français ou étrangers, des laboratoires publics ou privés. 


\title{
A biodegradation study of poly(3-hydroxybutyrate-co-3-hydroxyvalerate)/ organoclay nanocomposites in various environmental conditions
}

Kahina Iggui ${ }^{\text {a, b}}$, Nicolas Le Moigne ${ }^{\text {b, }}$, Mustapha Kaci ${ }^{a}$, Simon Cambe ${ }^{b}$, Jean-Régis Degorce-Dumas ${ }^{\text {b }}$, Anne Bergeret ${ }^{\mathrm{b}}$

a Laboratoire des Matériaux Polymères Avancés, Faculté de Technologie, Université de Bejaia 06000, Algeria

${ }^{\mathrm{b}}$ Centre des Matériaux des Mines d'Alès $(\mathrm{C} 2 \mathrm{MA})^{1}$, Ecole des Mines d'Alès, 6 avenue de Clavières, 30319 Alès Cedex, France

\begin{abstract}
A B S T R A C T
Poly(3-hydroxybutyrate-co-3-hydroxyvalerate) (PHBV)/organo-modified montmorillonite (OMMT) nanocomposite films were prepared by melt compounding and cast-film extrusion at various loading rates, i.e. 1, 3 and $5 \mathrm{wt}$ \%. The effect of OMMT on the biodegradability of produced PHBV nanocomposite films was investigated under controlled conditions in aqueous medium $\left(20^{\circ} \mathrm{C}\right.$ for 28 days) by monitoring the biochemical oxygen demand (BOD), and under laboratory-scale composting conditions $\left(58^{\circ} \mathrm{C}\right.$ for 70 days) by monitoring the weight and surface loss. The microstructural and macromolecular changes were monitored during the biodegradation process by means of scanning transmission electron microscopy (STEM), differential scanning calorimetry (DSC) and size exclusion chromatography (SEC) analysis. The initial microstructure of the nanocomposites samples exhibited an intercalated structure with a good clay/matrix affinity. BOD evolution in aqueous conditions as well as surface and weight loss in composting conditions indicated that the biodegradation rate of PHBV nanocomposites was lower than neat PHBV, which supports a barrier effect of OMMT. This was confirmed by the surface erosion observed through SEM accompanied by a significant decrease of the average molecular weight in the bulk of the films. Our results demonstrated that the biodegradation of PHBV and nanocomposite films occurred by combined hydrolytic and enzymatic processes, at the surface as well as in the bulk of the material. DSC analysis also revealed no change in the degree of crystallinity, which suggests that the amorphous and crystalline phases were degraded at same rate.
\end{abstract}

Keywords:

Poly(3-hydroxybutyrate-co-3-

hydroxyvalerate) (PHBV)

Nanocomposite

Clay

Biodegradation

Compost

\section{Introduction}

The combination of both ecological context and decrease in oil resources encouraged research and development on biodegradable polymers. Among them, poly(hydroxyalcanoates) (PHAs) are widely studied as they are fully biodegradable, biocompatible, and possess properties close to those of some synthetic thermoplastics such as polypropylene and polyethylene. Thus, they can be used alternatively in several applications, involving agriculture, packaging and biomedical domains [1-4]. Poly(3-hydroxybutyrate) (PHB) is the main polymer of the PHA family. It is characterized by a

\footnotetext{
* Corresponding author. Tel.: +33(0)4 667853 02; fax: +33(0)4 66785365 .

1 E-mail address: Nicolas.Le-Moigne@mines-ales.fr (N. Le Moigne).

(EPNOE), www.epnoe.eu.
}

poor thermal stability, a high crystallinity, making it difficult to process, and its brittleness limit up to now its large commercial implementation [3]. Furthermore, poly(hydroxybutyrate-cohydroxyvalerate) (PHBV) matrices present better mechanical properties, lower melting temperature and an extended processing window [4] as compared to poly(hydroxybutyrate) (PHB) matrix. Recently, biopolyester nanocomposites have attracted considerable scientific interest. It has been reported that the dispersion of clays within the polymeric matrices can improve some properties of the material such as thermal, mechanical and barrier properties [3-7]. However, little is known regarding the environmental biodegradability and the waste management through composting of such nanocomposite materials and only a few works were reported in literature. The biodegradation of PHB and its organo-modified montmorillonite (OMMT) based nanocomposites, prepared by melt compounding, was investigated in a compost medium at room temperature and $60{ }^{\circ} \mathrm{C}$ by Maiti et al. [8]. The results showed that 
the biodegradation rate of PHB was enhanced in the presence of clays at both test temperatures. Furthermore, the biodegradation in soil suspension of PHBV/OMMT nanocomposites prepared through solution intercalation was described by Wang et al. [9]. The authors reported a decrease in the biodegradation rate with increasing amounts of OMMT. Recently, the influence of different organoclays on the disintegrability of PHB nanocomposites in composting conditions was evaluated by Puglia et al. [10]. Three different types of montmorillonite were used, i.e. an unmodified sodium montmorillonite CloisiteNa ${ }^{+} \odot$, and chemically modified montmorillonites Cloisite $15 \mathrm{~A} \odot$ and $93 \mathrm{~A} \odot$, and incorporated in PHB through solution intercalation route. The results indicated that the rate of biodegradation was lower for nanocomposites than neat PHB and depends on the type of clays, the degradation of Cloisite $\mathrm{Na}^{+} \odot$ based nanocomposite being enhanced as compared to OMMT based nanocomposites. From the above studies, contradictory results have been reported concerning the effect of clays on PHAs based nanocomposites and no results have been reported on the biodegradation behavior in composting conditions of PHBV in presence of organo-modified Cloisite $30 \mathrm{~B} \odot$, which is a widely used clay in biopolyester matrices.

Complementing to previous studies and aiming to better understand the effects of OMMT on the biodegradability of nanocomposites based biopolyesters, the biodegradation behavior of PHBV/OMMT nanocomposites prepared by cast-film extrusion was investigated under controlled conditions, both in aqueous medium (20 ${ }^{\circ} \mathrm{C}$ for 28 days) and laboratory-scale composting conditions (58 ${ }^{\circ} \mathrm{C}$ for 70 days). The initial microstructure and thermomechanical properties of PHBV/clays nanocomposites were characterized so as to investigate the quality of the clay dispersion and the clays/matrix interaction. The biodegradability of the exposed samples was studied by monitoring the biochemical oxygen demand (BOD) in aqueous conditions and the disintegrability in composting conditions. The results are discussed from the macrostructural to the macromolecular level considering the molecular weight distribution as well as the microstructural and morphological changes that occurred during biodegradation of the films.

\section{Experimental}

\subsection{Materials}

Poly(3-hydroxybutyrate-co-3-hydroxyvalerate) (PHBV) was supplied by Natureplast under the trade name PHI002@. It contains7 wt. \% of hydroxyvalerate (HV) and is nucleated with boron nitride. It is a semi-crystalline polymer with a glass transition temperature around $5{ }^{\circ} \mathrm{C}$ and a melting temperature of $155^{\circ} \mathrm{C}$ according to supplier datasheet. The clay used was supplied by Southern Clay Products, Inc. (USA) under the trade name Cloisite $30 \mathrm{~B} \odot$, named $\mathrm{C} 30 \mathrm{~B}$ in the present study. According to the manufacturer, it was organically modified by tallow alkyl bis(2hydroxyethyl) methylammoniumchloride with a cation exchange capacity of $90 \mathrm{meq} / 100 \mathrm{~g}$. The tallow alkyl is a mixture that contains $65 \%$ C18, 30\% C16 and 5\% C14. C30B presents a moisture content $<3 \%$ and a weight loss on ignition of $30 \%$. To limit hydrolysis of PHBV upon processing, both matrix and clays were dried under vacuum overnight at $80^{\circ} \mathrm{C}$ prior to use.

\subsection{Preparation of nanocomposites films}

PHBV nanocomposites with 1,3 and 5 wt\% of C30B were prepared by melt compounding using a PHBV masterbatch containing $20 \mathrm{wt} \%$ of C30B. The masterbatch was prepared using a co-rotating twin-screw extruder BC21 (Clextral, France) with a length (L) of
$900 \mathrm{~mm}$, a screw diameter (D) of $25 \mathrm{~mm}$ and a (L/D) of 36. The temperature and the twin-screw profile used are given in Fig. 1.

A parabolic temperature profile was used to limit thermal degradation of PHBV. The overall feed rate was $5 \mathrm{~kg} / \mathrm{h}$ and the screw speed was $250 \mathrm{rpm}$. The $\mathrm{C} 30 \mathrm{~B}$ clays were introduced in zone 4 . The melting of the PHBV and the mixing and the dispersion of the clays were ensured by a kneading section between zones 3 to 4 with stagger angles between the kneading paddles of $30^{\circ}$ and two reverse screws in zone 4 and 7. Extrudates were water-cooled at ambient temperature, then pelletized in-line to around $3 \mathrm{~mm}$ diameter and dried overnight at $80{ }^{\circ} \mathrm{C}$ under vacuum (100 mbar) Then, the nanocomposite films, named C-PHBV/C30B, at various contents of OMMT, i.e. 1, 3 and 5wt. \% were produced by masterbatch dilution with neat PHBV using a single-screw cast extruder with a length of $475 \mathrm{~mm}$ and a screw diameter of $19 \mathrm{~mm}$ and a (L/D) of 25 . Screw speed was $60 \mathrm{rpm}$ and the barrel to die temperature profile was $\left(155-175-177-160{ }^{\circ} \mathrm{C}\right)$. Finally, the melted nanocomposite compounds were stretched at the exit of the flat die between two chill rolls at $7{ }^{\circ} \mathrm{C}$, so that surfaces of the films were quenched, while their core was slowly cooled down on a conveyor belt. The stretching ratio was low since longitudinal and transverse mechanical properties of the films (not presented in the paper) were similar. The resulting films were then stored at $20^{\circ} \mathrm{C}$ and $2 \%$ $\mathrm{RH}$, and exhibited an average thickness of about $500 \mu \mathrm{m}$ and a $80 \mathrm{~mm}$ width. The designation of the different produced nanocomposite films are listed in Table 1.

\subsection{Microtructural and macromolecular analysis}

\subsubsection{Wide angle X-ray diffraction (WAXD)}

WAXD was used to determine the interlayer spacing between stacked organoclay platelets and hence their dispersion state within the PHBV matrix. WAXD measurements were performed at room temperature using an AXS D8 Advance diffractometer (Bruker, Germany) equipped with a Cu cathode $(\lambda=1,5405 \AA$ ) and a Vantec detector. Measurements were performed directly on films in reflection mode in the range $2 \theta=1.5-10^{\circ}$ with a step size of $0.007^{\circ}$ and a step time of $24.5 \mathrm{~s}$. The interlayer distance $d_{001}$ was determined from the (001) diffraction peak using Bragg'slaw Eq (1):

$\lambda=2 d \sin \theta$

\subsubsection{Scanning (SEM) and transmission electron (STEM)}

microscopy observations

STEM and SEM images of cast PHBV and C-PHBV/C30B nanocomposite films were captured using a QUANTA 200 FEG (FEI Company) environmental scanning electron microscope at an acceleration voltage of 7-10 keV. Prior to observations in scanning mode (SEM), the fracture surfaces of the films were sputter coated with carbon using a Carbon Evaporator Device CED030 (Balzers), to ensure good surface conductivity and avoid any degradation. For STEM observations, the different samples were prepared using an ultramicrotome (Leica Ultracut) equipped with a diamond knife. The ultrathin sections were cut at $-80^{\circ}$ Cand were deposited on $\mathrm{Cu}$ grids.

\subsubsection{Size exclusion chromatography (SEC)}

The molecular weight distribution (MWD) of PHBV was determined by size exclusion chromatography (SEC) using a OmniSECT60A system. Neat PHBV, cast PHBV and C-PHBV/C30B nanocomposites (typically $20 \mathrm{mg}$ ) were dissolved in $2 \mathrm{ml}$ of chloroform over $1 \mathrm{~h}$ at $60^{\circ} \mathrm{C}$. Before injection, all samples were filtered through a Phenex PTFE $0.2 \mu \mathrm{m}$ filter to remove any insoluble fractions or clay. SEC experiments were conducted in a Waters 410 Differential Refractometer using a column PL Gel 5- $\mu$ m Mixed-C 


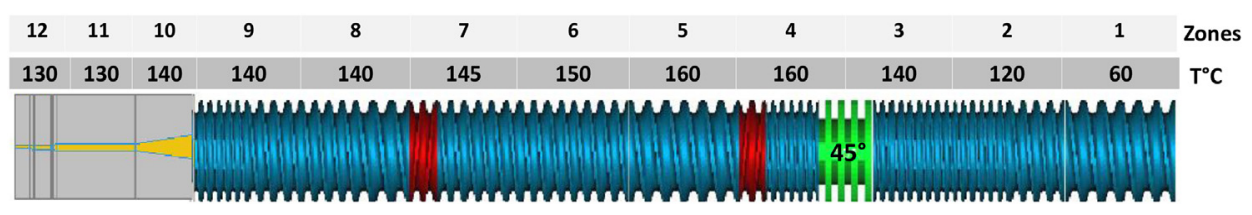

Fig. 1. Screw and temperature profile used for masterbatch compounding.

$(1 \times 600 \mathrm{~mm})$. The column eluent was chloroform at a flow rate of $1 \mathrm{~mL} / \mathrm{min}$. The average molecular weights in weight $\overline{M_{w}}$ and in number $\overline{M_{n}}$ as well as the polydispersity index Ip were determined. Two specimens of each sample were tested, and the average results were reported.

\subsubsection{Differential scanning calorimetry (DSC)}

Differential scanning calorimetry analysis (DSC) was performed on a Pyris Diamond DSC thermal analysis system (Perkin Elmer) equipped with an Intracooler II. Small amounts (15-20 mg) of dried samples were placed into aluminum pans. Heating and cooling scans were performed at a scanning rate of $10^{\circ} \mathrm{C} \mathrm{min}^{-1}$ from 30 to $200{ }^{\circ} \mathrm{C}$, using $\mathrm{N}_{2}$ as the purging gas. At least three specimens were tested for each sample. An empty aluminum pan was used as reference and the crystallization exotherm and melting endotherms were analyzed. The degree of crystallinity $\left(X_{c}\right)$ was determined according to Eq. (2):

$X_{c}=\frac{\Delta H_{m}}{W \cdot \Delta H_{m}^{0}} \times 100$

where $\Delta H_{m}\left(\mathrm{~J} \mathrm{~g}^{-1}\right)$ is the melting enthalpy of the polymer matrix PHBV, $W$ is polymer weight fraction (PHBV) in the sample, calculated from the real content of $\mathrm{C} 30 \mathrm{~B}$, and $\Delta H_{m}^{0}$ is the melting enthalpy of a pure crystal and $\Delta H_{m}^{0}=-146 \mathrm{~J} \mathrm{~g}^{-1}$, found for PHB by Barham et al. [11]. No values for PHBV with varying valerate amounts are referenced in literature.

\subsubsection{Dynamic mechanical analysis (DMA)}

Thermo-mechanical behavior of cast PHBV and C-PHBV/C30B nanocomposite films was investigated in the vicinity of the $\alpha$ transition using a dynamic mechanical analyzer DMA 50 (MetravibO3dB, France). Three rectangular specimens of each sample with a dimension of approximately $35 \times 5 \times 0.5 \mathrm{~mm}^{3}$ were tested. The measurements were performed in shear mode at $5 \mathrm{~Hz}$ and $5 \mu \mathrm{m}$ of amplitude and the temperature range was varied between -20 and $120{ }^{\circ} \mathrm{C}$ at a heating rate of $3{ }^{\circ} \mathrm{C} / \mathrm{min}$. Storage modulus $\left(\mathrm{G}^{\prime}\right)$, loss modulus $\left(G^{\prime \prime}\right)$ and loss factor $(\tan \delta)$ were determined.

\subsection{Biodegradability evaluation}

The biodegradability of cast PHBV and C-PHBV/C30B nanocomposite films was studied both in aqueous media and in laboratory-scale composting conditions.

Table 1

Formulations used in this study.

\begin{tabular}{llll}
\hline Sample designations & PHBV (wt\%) & \multicolumn{2}{l}{ C30B content (wt\%) } \\
\cline { 3 - 4 } & & Theoretical & Real $^{\mathrm{a}}$ \\
\hline Neat PHBV & 100 & 0 & 0 \\
Cast PHBV & 100 & 0 & 0 \\
C-PHBV/1C30B & 99 & 1 & $1.57 \pm 0.42$ \\
C-PHBV/3C30B & 97 & 3 & $3.29 \pm 0.71$ \\
C-PHBV/5C30B & 95 & 5 & $5.86 \pm 0.67$ \\
\hline
\end{tabular}

\footnotetext{
a The real clay contents were determined by thermogravimetric analysis (TGA) at a heating rate of $10^{\circ} \mathrm{C} / \mathrm{min}$ under nitrogen atmosphere.
}

\subsubsection{Aqueous biodegradation conditions}

The biochemical oxygen demand (BOD) of cast PHBV and CPHBV/C30B nanocomposite films was carried out according to the EN ISO 14851 method [12]. All tests were performed under aerobic conditions at $20{ }^{\circ} \mathrm{C}$ using OxiTop ${ }^{\mathbb{B}}$ vessels. Films were crushed to powder with an average diameter of $500 \mu \mathrm{m}$. Routinely, $20 \mathrm{mg}$ of each material were placed in a BOD reactor in the presence of a $365 \mathrm{ml}$ mineral solution (see EN ISO 14851 protocol) and $1 \mathrm{ml}$ of settled activated sludges (supernatant was collected after one hour) from local urban wastewater treatment plant (Alès, France). The biodegradation test was carried out for 28 days, and the biochemical oxygen demand (BOD) was measured daily. Measurements were triplicated and results are given with $\pm 8 \%$ standard deviation. The biodegradation percentage of samples was calculated as follows:

$B O D_{s}=\frac{B O D_{m}-B O D_{\text {nit }}}{\rho_{T C}}$

and

$D t=\frac{B O D_{s}}{T h O D} \times 100$

where $\operatorname{bod}_{\mathrm{s}}\left(\mathrm{mg}_{\mathrm{O} 2} / \mathrm{g}_{\text {material }}\right)$ is the specific BOD, $B O D_{m}\left(\mathrm{mg}_{\mathrm{O} 2} / \mathrm{L}\right)$ is the measured BOD, $B O D_{\text {nit }}\left(\mathrm{mg}_{02} / \mathrm{L}\right)$ is the nitrification BOD, $\rho_{T C}(\mathrm{~g} / \mathrm{L})$ is the material concentration, $D t(\%)$ is the biodegradation rate, and ThOD $\left(\mathrm{mg}_{02} / \mathrm{g}_{\text {material }}\right)$ is the Theoretical Oxygen Demand and equals to $1692 \mathrm{mg} / \mathrm{O}_{2} / \mathrm{g}_{\text {material }}$ for PHBV determined as follows:

$$
\begin{aligned}
\text { ThOD }= & 93 \%\left(\frac{16[2 c+0.5 h-o]}{M_{r}}\right)_{\mathrm{PHB}} \\
& +7 \%\left(\frac{16[2 c+0.5 h-o]}{M_{r}}\right)_{\mathrm{PHV}}
\end{aligned}
$$

where $c, h$ and $o$ are the atomic mass of $\mathrm{C}, \mathrm{O}$ and $\mathrm{H}$, respectively, and $\mathrm{Mr}$ is the relative molecular mass of PHB and PHV.

\subsubsection{Biodegradation under laboratory-scale composting conditions}

The biodegradability of cast PHBV and C-PHBV/3C30B nanocomposite films under conditions simulating an intensive aerobic composting process was carried out as described in EN ISO 20200 standards [13]. Solid synthetic waste was prepared by mixing $10 \%$ $\mathrm{w} / \mathrm{w}$ of compost supplied by composting unit SITA (Alès, France), with $40 \% \mathrm{w} / \mathrm{w}$ sawdust supplied by sawmill Nogaret (Alès, France), with $30 \% \mathrm{w} / \mathrm{w}$ rabbit food, $10 \% \mathrm{w} / \mathrm{w}$ starch, $5 \% \mathrm{w} / \mathrm{w}$ sugar, $4 \% \mathrm{w} / \mathrm{w}$ corn oil and $1 \% \mathrm{w} / \mathrm{w}$ urea. After mixing, the water content of the mixed substrate was adjusted to $55 \%$.Water was then added periodically by adjusting the weight of the containers according to the procedure described in EN ISO 20200 standards, so as to maintain a sufficient and constant relative humidity in the compost medium, and the aerobic conditions were ensured by mixing it softly. Disks (diameter $20 \mathrm{~mm}$, average thickness $500 \mu \mathrm{m}$ ) were cutted from Cast PHBV and C-PHBV/3C30B nanocomposite films. Each disk was weighed and then buried at $5-6 \mathrm{~cm}$ depth in aluminum containers 
$\left(26 \times 13 \times 6 \mathrm{~cm}^{3}\right)$ containing $500 \mathrm{gr}$ of compost medium (10 disks per containers). Containers were incubated at $58{ }^{\circ} \mathrm{C}$ for 70 days in an air circulation oven (Heraeus). The compost $\mathrm{pH}$ was measured at different degradation times ( $1 \mathrm{~g}$ in $20 \mathrm{ml}$ of deionized water) by $\mathrm{pH}$ meter (Jenway 3345 Ion Mater). Disks were recovered from the containers every week, washed with distilled water, dried under vacuum overnight at $50{ }^{\circ} \mathrm{C}$ and reweighed. The disintegrability of the samples was calculated by normalizing the sample weight, at different composting times, to the initial weight using Equation (6):

disintegrability $(\%)=\frac{\text { Winitial }- \text { Wfinal }}{\text { Winitial }} \times 100$

where, $W_{\text {initial }}$ and $W_{\text {final }}$ are the weight $(\mathrm{g})$ of samples before and after composting test, respectively. The morphological, microstructural and macromolecular changes of the disks were characterized during composting as follows: (i) microphotographs of degraded samples with a digital camera (Pentax K7) and SEM observations; (ii) average molecular weights measurements by SEC and (iii) thermal properties through DSC analysis.

\section{Results and discussion}

\subsection{Characterization of nanocomposite films prior to biodegradation}

\subsubsection{Clay dispersion and molecular weight distribution (MWD)}

WAXD patterns of raw C30B, cast PHBV and C-PHBV/C30B nanocomposites are presented in Fig. 2. A weak and broad peak is observed in the WAXD pattern of cast PHBV at $2.5^{\circ}$, whereas raw C30B clays exhibit a strong peak at around $4.8^{\circ}$, corresponding to an interlayer spacing of $18.2 \AA$. In the case of C-PHBV/C30B nanocomposites, diffraction peaks appear at much lower angles corresponding to $d_{001}$ distances of $35.5,33.6$ and $32.9 \AA$ for 1,3 and $5 w t \%$ of $\mathrm{C} 30 \mathrm{~B}$, respectively. The shift of the organoclay diffraction peak to lower angles suggests an intercalation of polymer chains within the interlayer space of the clays. This intercalated structure is attributed to the favorable interactions between PHBV and C30B which originates from the strong hydrogen bonding between the ester carbonyl groups of PHBV and the hydroxyl groups in the gallery of C30B [14]. However, it should be noticed that the interlayer distances of C-PHBV/C30B nanocomposites are lower compared to the literature data. Bordes et al. [5] and Choi et al. [14] found interlayer

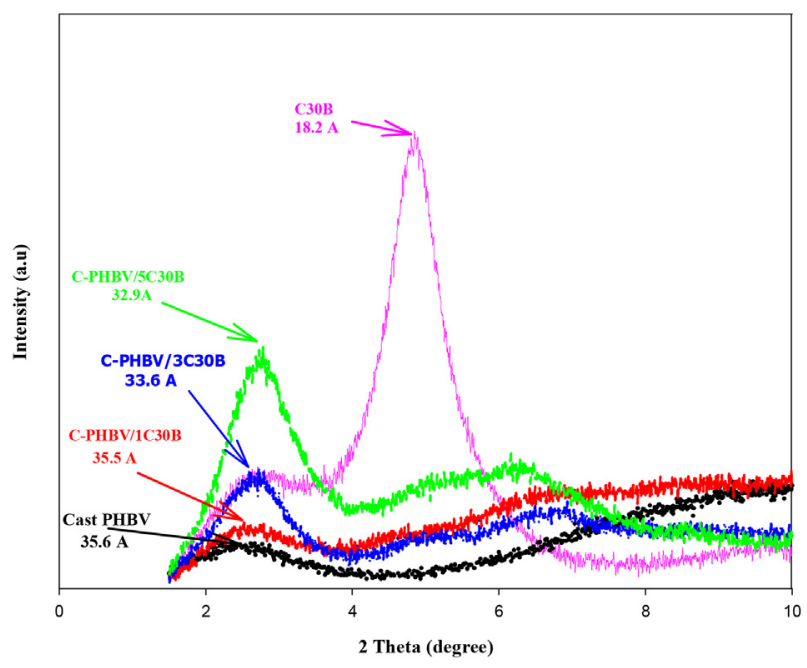

Fig. 2. WAXD patterns of cast PHBV and C-PHBV/C30B nanocomposites. distances of $36.8 \AA$ and $38.5 \AA$ for PHBV/2 and 3\% C30B and PHBV/ $2.6 \%$ С $30 \mathrm{~B}$ nanocomposites prepared by melt intercalation, respectively. Our results suggest that a significant fraction of clays has been dispersed in the intercalated form or as individual platelets while a small fraction remained in the form of micrometric aggregates of tactoids.

Dispersion of C30B in PHBV was also observed by STEM. The images in Fig. 3 confirm the WAXD results, showing the formation of intercalated nanocomposites with few individually dispersed platelets attesting for a partial exfoliation of organoclays. From the STEM image (a) of cast PHBV, some black circular particles of boron nitride, i.e. the nucleating agent present in the PHBV matrix were observed.

SEC results are summarized in Table 2. A mono modal distribution was observed whatever the analyzed sample. Reductions of about $23 \%$ in $\overline{M_{w}}, 7 \%$ in $\overline{M_{n}}$ and $16 \%$ in Ip were observed between neat and cast PHBV. These results are consistent with similar studies described in the literature. Indeed, Renstad et al. [15] compared different processing conditions (screw speed, temperature) of PHBV through internal mixing and concluded that $\overline{M_{w}}$ significantly decreases with increasing screw speeds and temperatures. For example, a $30^{\circ} \mathrm{C}$ increase in the processing temperature was responsible for a $30-40 \%$ decrease in $\overline{M_{w}}$. For nanocomposite films, similar evolution of $\overline{M_{w}}$ and $\overline{M_{n}}$ with increasing organoclay contents was observed. $\overline{M_{w}}$ decreased by about $10 \%, 19 \%$ and $25 \%$ for 1,3 and $5 \mathrm{wt} \%$ of C30B, respectively, compared to neat PHBV. $\overline{M_{n}}$ slightly increased by $4 \%$ with the incorporation of $1 \mathrm{wt} \%$ of $\mathrm{C} 30 \mathrm{~B}$, then significantly decreased by $22 \%$ and $31 \%$ with the incorporation of 3 and $5 \mathrm{wt} \%$ of C30B, respectively, compared to neat PHBV. It can be considered that Ip remained almost constant around 3. Bordes et al. [5] and Cabedo et al. [16] observed more pronounced degradation; with a decrease of $\overline{M_{w}}$ by 40 and $60 \%$ for PHB $/ 5 \%$ C30B and PHBV $/ 4.4 \%$ C30B nanocomposites, respectively, and by $80 \%$ for PHBV with $5 \%$ of organically modified montmorillonite Cloisite 20A. This significant degradation could be due to the presence of $\mathrm{Al}$ Lewis acid sites in the inorganic layers which catalyzes the hydrolysis of ester linkages of PHBV [3,8] and to the decomposition of the organoclays upon extrusion that could also catalyze the PHBV degradation $[4,17]$. From our results, it can be also observed lower average molecular weights for cast PHBV $\left(\overline{M_{w}}=290862 \mathrm{~g} / \mathrm{mol}\right)$ than for casted $\mathrm{PHBV} / 1$ and 3\% C30B nanocomposites $\left(\overline{M_{w}}=336463\right.$ and $305510 \mathrm{~g} / \mathrm{mol}$, respectively). This suggests a protecting role of the clays at low contents upon processing that limits the depolymerization of the chains as compared with pure cast PHBV. Therefore, these significant variations in the initial PHBV chain length should influence the biodegradation behavior of the samples.

\subsubsection{Dynamic mechanical behavior of nanocomposite films and clays/matrix interaction}

Dynamic mechanical measurements were performed on cast PHBV and nanocomposite films to investigate the effect of the clay dispersion on their thermo-mechanical properties and the clay/ matrix affinity. Fig. 4 represents the curves of storage modulus $\left(G^{\prime}\right)$ and loss factor $(\tan \delta)$ as function of temperature for cast PHBV and C-PHBV/C30B nanocomposites. In Fig. 4a, it is clearly observed that the storage modulus for C-PHBV/3C30B and C-PHBV/5C30B nanocomposites are very close and much higher over the whole temperature range compared to those of cast PHBV and C-PHBV/1C30B nanocomposite. This behavior indicates that the addition of more than $1 \%$ of clays enhanced the elastic properties of PHBV matrix. In Fig. $4 \mathrm{~b}$, it is observed that the presence of clays had an influence on the shape of $\tan \delta$ signals, indicating a shift in the $\alpha$-transition temperature related to $\mathrm{Tg}$ towards higher temperatures for the nanocomposites. The cast PHBV indeed exhibits an $\alpha$-transition at 

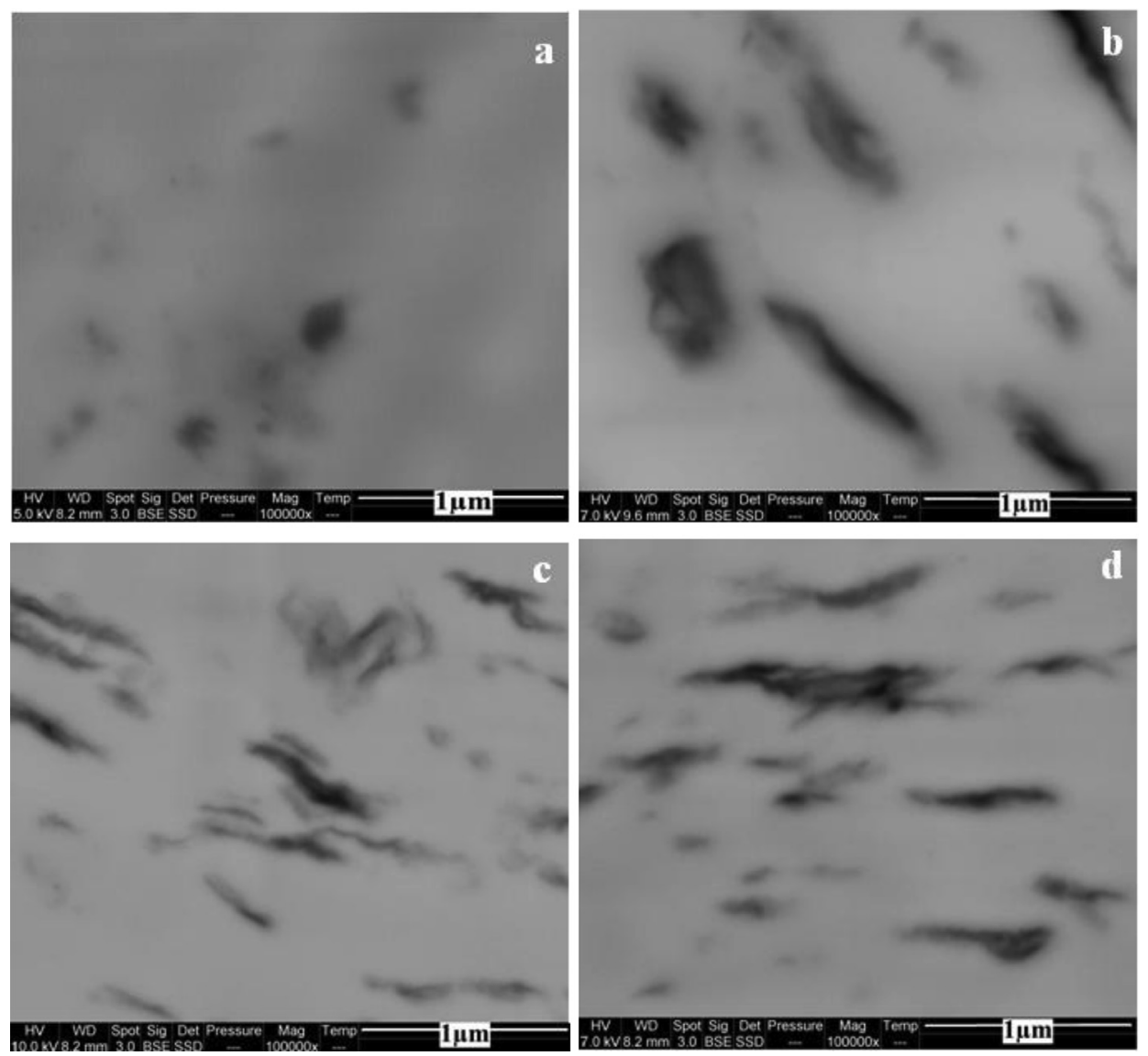

Fig. 3. STEM micrographs of (a) cast PHBV, (b) C-PHBV/1C30B, (c) C-PHBV/3C30B, (d) C-PHBV/5C30B.

Table 2

SEC results (weight-average molecular weight $\overline{M_{w}}$, number-average molecular weight $\overline{M_{n}}$ and polydispersity index $\mathrm{I}_{\mathrm{P}}$ ) for neat and cast PHBV and C-PHBV/C30B nanocomposites.

\begin{tabular}{llll}
\hline Sample & $\overline{M_{w}}(\mathrm{~g} / \mathrm{mol})$ & $\overline{M_{n}}(\mathrm{~g} / \mathrm{mol})$ & $I_{P}$ \\
\hline Neat PHBV & $375835 \pm 3594$ & $121747 \pm 6779$ & $3.1 \pm 0.1$ \\
Cast PHBV & $290862 \pm 2881$ & $112956 \pm 12632$ & $2.6 \pm 0.3$ \\
C-PHBV/1C30B & $336463 \pm 9721$ & $126357 \pm 8632$ & $2.7 \pm 0.1$ \\
C-PHBV/3C30B & $305510 \pm 1971$ & $94648 \pm 5460$ & $3.2 \pm 0.2$ \\
C-PHBV/5C30B & $280932 \pm 1960$ & $84577 \pm 96$ & $3.3 \pm 0.0$ \\
\hline
\end{tabular}

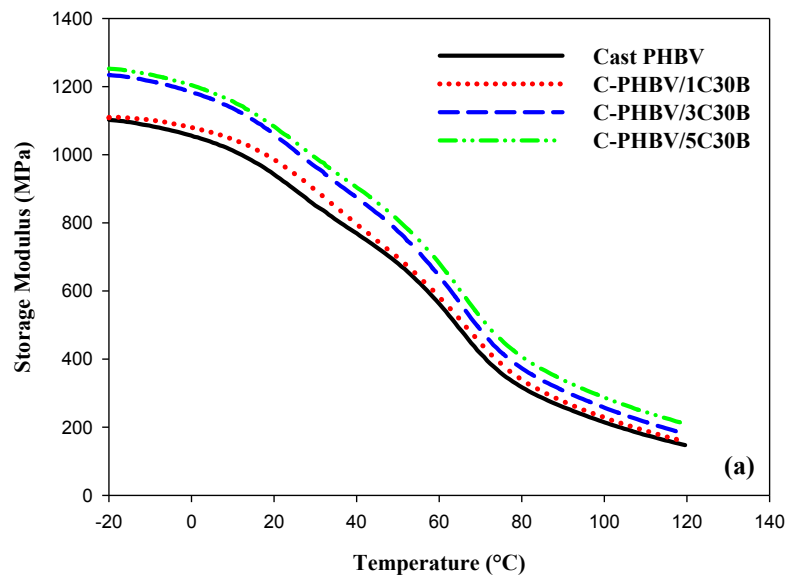

$28.29 \pm 1.60{ }^{\circ} \mathrm{C}$ which is shifted to $33.37 \pm 0.04{ }^{\circ} \mathrm{C}, 29.84 \pm 0.48^{\circ} \mathrm{C}$ and $31.25 \pm 1.24{ }^{\circ} \mathrm{C}$ for nanocomposites loaded at 1,3 and $5 \mathrm{wt} \%$, respectively. According to Chen et al. [6], the enhancement of the $\alpha$ transition temperature and modulus of PHBV/OMMT can be attributed to the adhesion between the polymer and the surface of the dispersed layered silicates that exhibits high specific surfaces. This restricts the local motions of the polymer chains near the organic/inorganic interface and should play a role in the biodegradation behavior of nanocomposite samples. The improvement in

Fig. 4. Temperature dependence of (a) storage modulus $\left(\mathrm{G}^{\prime}\right)$ and $(\mathrm{b})$ loss factor $(\tan \delta)$ for cast PHBV and C-PHBV/3C30B nanocomposite films. 
thermo-mechanical properties also indicates that the clays were well dispersed in PHBV matrix, and intercalated nanocomposites were formed. This result is in accordance with the STEM and WAXD observations, regarding the dispersion state of the clays.

\subsection{Biodegradation behavior of PHBV and nanocomposite films}

\subsubsection{Biodegradation in aqueous conditions: monitoring the} biological oxygen demand

Fig. 5 shows typical BOD-biodegradation curves of cast PHBV and C-PHBV/C30B nanocomposite films with cellulose as reference. The biodegradation rate of cast PHBV increased with time to reach $77 \%$ after 28 days of incubation. The rate of biodegradation was lower for nanocomposite films compared to cast PHBV film, suggesting that degradation was strongly influenced by the organoclay content. After 28 days, the biodegradation rate for C-PHBV/1C30B, C-PHBV $/ 3$ C $30 \mathrm{~B}$ and C-PHBV $/ 5 \mathrm{C} 30 \mathrm{~B}$ were $72 \%, 24 \%$ and $35 \%$, respectively. As shown in Fig. 5, the profiles of the biodegradation curves for C-PHBV/3C30B and C-PHBV/5C30B nanocomposites showed a marked latency period of about 7 and 9 days, respectively, as well as a significant decrease of the biodegradation kinetics. It has to be noticed that the lower biodegradation rate observed for $\mathrm{C}$ PHBV/3C30B as compared to C-PHBV/5C30B should be related to the lower molecular weight of the latter at the initial state prior to biodegradation (see also Table 2), which should ease the biodegradation process. The decrease of biodegradability in presence of organoclays, as determined by gravimetric measurements, has already been observed by Wang et al. [9] for PHBV/OMMT in soil suspension. This was attributed to the barrier effect of dispersed clays that should reduce the diffusion of water and microorganisms from the surface into the bulk of the material [18], thus hampering the hydrolysis and the further biodegradation of PHBV chains. In addition, the quaternary ammonium salt present in organomodified clay could act as a surfactant germicide [9], as well as a bacterial adsorber limiting then the microbial activity towards PHBV chains.

\subsubsection{Biodegradation under laboratory-scale composting} conditions: changes from the macrostructural to the macromolecular level

3.2.2.1. Effect of PHBV and nanocomposite films on compost $\mathrm{pH}$. The $\mathrm{pH}$ of neat compost and composts containing cast PHBV and PHBV/3C30B nanocomposite films were measured at different

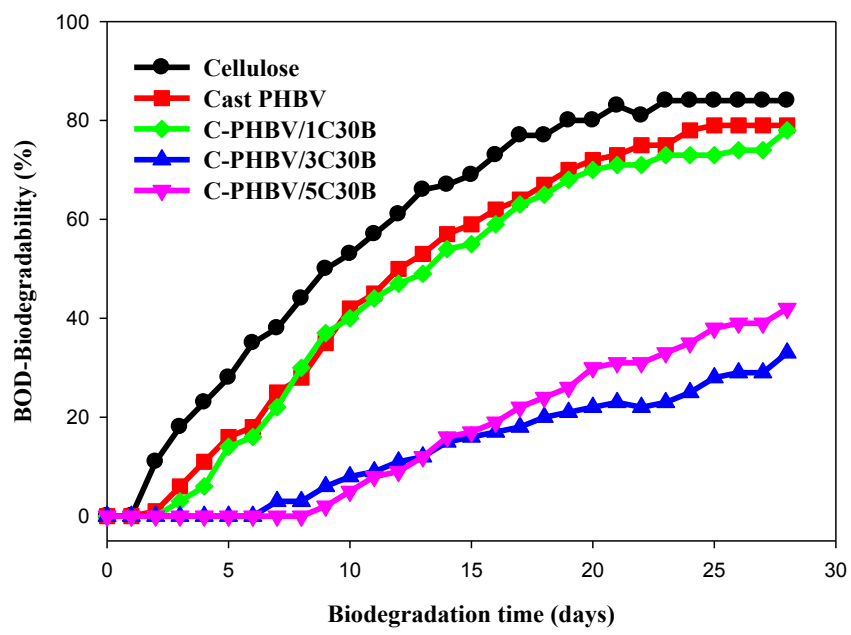

Fig. 5. BOD curves of cast $\mathrm{PHBV}$ and $\mathrm{C}-\mathrm{PHBV} / \mathrm{C} 30 \mathrm{~B}$ nanocomposites in aqueous conditions. degradation times (Fig. 6). Changes in pH curves are similar to the theoretical evolution described by Mustin for a compost [19]: (i) a mesophilic phase occurring at low temperatures (from $20^{\circ} \mathrm{C}$ to $45^{\circ} \mathrm{C}$ ), characterized by a decrease of the $\mathrm{pH}$ due to the production of organic acids from easily degradable materials (monosaccharides, starch, lipids ...); (ii) then, a thermophilic phase occurring at higher temperature (up to $70^{\circ} \mathrm{C}$ ), characterized by an increase of the $\mathrm{pH}$, the hydrolysis of high molecular weight materials such as cellulose, lignin and other polymeric materials present or introduced in the compost, and the assimilation and the transformation of readily biodegradable organic matter (oligomers and monomers) into $\mathrm{CO}_{2}$ and $\mathrm{H}_{2} \mathrm{O}$; (iii) finally, a maturation stage occurring at stabilized $\mathrm{pH}$ and decreasing, characterized by the final transformation of remaining organic matter and humus, also called humification process. Moreover, our data confirm the validity of the test as required by EN ISO 16929 [20], which specifies that during composting the $\mathrm{pH}$ should increase to a value above 7 and does not fall below 5. Indeed, the initial $\mathrm{pH}$ values of the neat compost and composts containing cast PHBV and C-PHBV/3C30B films were 6.65 , 6.85 and 6.85 , respectively. After 3-7 days, the $\mathrm{pH}$ dropped to an average value of 5 , which is characteristic of the mesophilic phase and consistent with literature. Between 3 and 7days and 15 days the $\mathrm{pH}$ increased to an average value of 8.5 , related to the transition from the mesophilic to thermophilic phase. After 35 days, the $\mathrm{pH}$ remained constant to an average value of 7.5 and 8 for the neat compost and the composts containing PHBV and PHBV nanocomposite films, respectively, characterizing the maturation stage. Wang et al. [9] observed an increase of the pH from 6.8 to 7.2 followed by stabilization for PHBV/OMMT in soil suspension. Lotto et al. [21] also observed a slight increase of $\mathrm{pH}$ up to 8-9 during composting of poly( $\varepsilon$-caprolactone) (PCL), PHB and PHBV in soil compost. Weng et al. [22] observed an increase in $\mathrm{pH}$ value from 6.4 to 8.8 during the biodegradation of PHBV films under pilot-scale composting conditions (ISO 16929). In the present study, it has to be noticed that the presence of PHBV and nanocomposite films in the compost seems to modify the microbial activity, as the $\mathrm{pH}$ evolution was delayed of about 5 days. This suggests a longer acclimatization period for the microbial metabolism in the presence of PHBV and nanocomposite films within the compost.

3.2.2.2. Disintegrability and morphological changes. The disintegrability values of cast PHBV and C-PHBV/3C30B nanocomposite films during composting are shown in Fig. 7. During the first 15 days, no

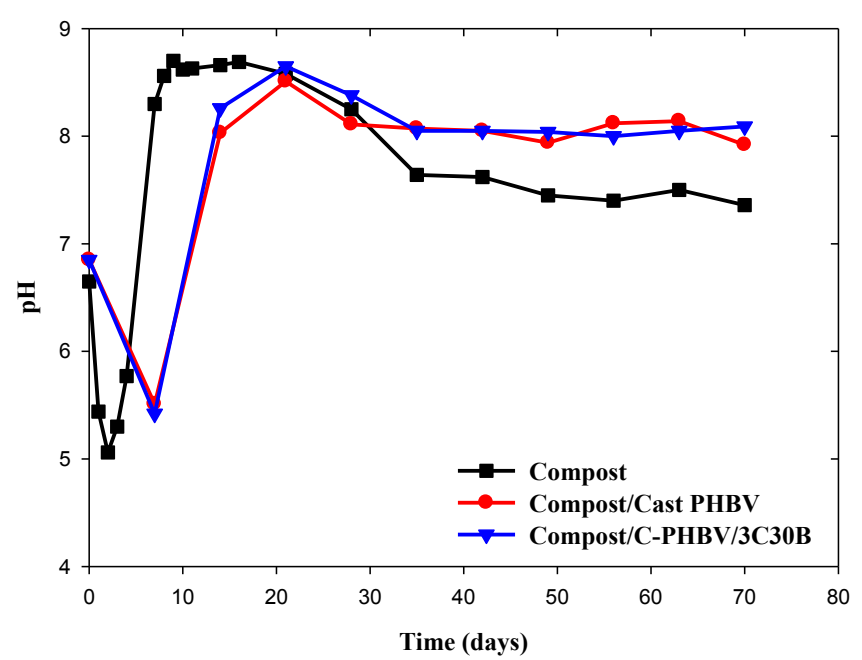

Fig. 6. Evolution of $\mathrm{pH}$ during composting for cast PHBV and C-PHBV/C30B. 


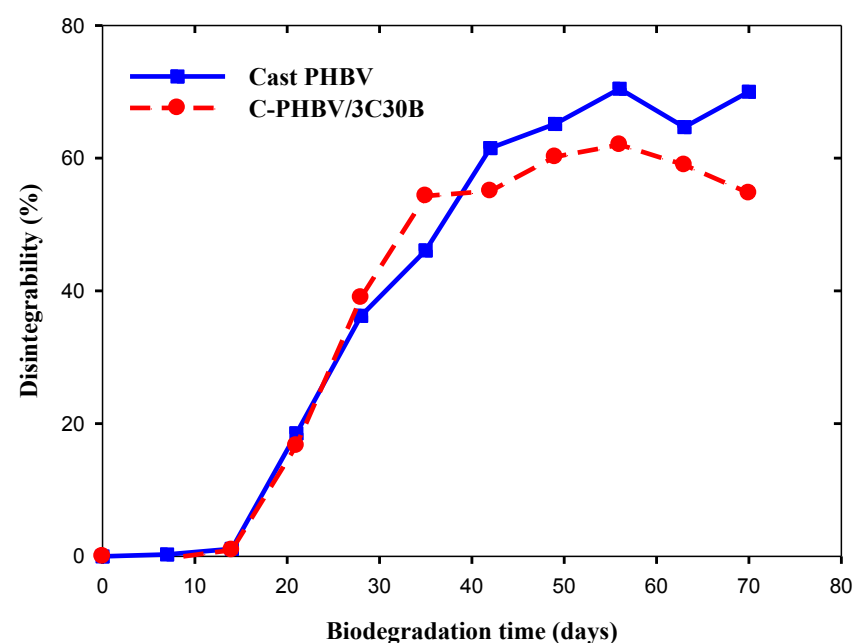

Fig. 7. Disintegrability of cast $\mathrm{PHBV}$ and $\mathrm{C}-\mathrm{PHBV} / \mathrm{C} 30 \mathrm{~B}$ nanocomposite films in laboratory-scale composting conditions.

measurable change in weight was observed for both materials. This is characteristic of the biodegradation stage in which only small molecules can be degraded. After 15 days, the maturation stage started and was characterized by a rapid increase of disintegrability values to reach a plateau above 50 days. This stage was also previously identified by the $\mathrm{pH}$ stabilization (Fig. 7) and is characterized by the biodegradation of high-molecular weight materials such as PHBV but also ligno-cellulosic biomass present in the compost. The weight loss of the films can thus be explained by the digestion of the degraded materials by microorganisms or their breakage into small fragments that cannot be found in the compost. The washing of the films before weighing is also responsible for the leaching of the smaller molecules present at the surface of the degraded films, and hence contributes to the weight loss $[10,23]$. The highest disintegrability was measured for PHBV films, with weight loss of $19 \%$ and $70 \%$ after 21 and 70 days, respectively. The biodegradation of nanocomposite films was much lower with disintegrability values of $17 \%$ and $55 \%$ for 21 and 70 days, respectively. This result is in accordance with BOD measurements recorded in aqueous conditions at $20{ }^{\circ} \mathrm{C}$, for which a limited biodegradation was observed with nanocomposite materials. Decreased biodegradability in the presence of organoclays was also reported by Wang et al. [9] for PHBV/OMMT nanocomposites in soil suspension at $28{ }^{\circ} \mathrm{C}$, Puglia et al. [10] for PHB/OMMT nanocomposites in laboratory-scale composting conditions (ISO 20200) and by Lee et al. [18] and Phua et al. [24] for aliphatic polyester APES/OMMT and PBS/OMMT in compost soil conditions at $30{ }^{\circ} \mathrm{C}$ and $60{ }^{\circ} \mathrm{C}$, respectively. On the other hand, increased biodegradability was observed by Puglia et al. [10] in the presence of unmodified MMT.
This was attributed to the Al Lewis acid sites and the hydrophilic nature of unmodified MMT which favor the presence of residual water and the hydrolysis of polymer chains into smaller molecules digestible by microorganisms.

Modifications of the morphology of cast PHBV and C-PHBV/ 3C30B nanocomposite films were investigated at different composting times by visual and SEM observations. As shown in Fig. 8, the photomicrographs of the films show a heterogeneous surface for all the samples, characterized by the presence of holes and cavities. This was more evident in the case of cast PHBV film after 49 days of incubation. These observations are consistent with the SEM pictures (Fig. 9) which show eroded surfaces with numerous cavities, the phenomenon being less pronounced for PHBV nanocomposite films.

3.2.2.3. Molecular weight distribution (MWD) changes. Using SEC analyses, the MWD of cast PHBV and C-PHBV/3C30B nanocomposite films were determined after 21 and 70 days of biodegradation. It was observed that MWD curves progressively shifted towards lower molecular weights with increasing biodegradation time (Fig. 10), indicating that the degradation of PHBV occurs by a chain scission mechanism. The values of $\overline{M_{n}}, \overline{M_{w}}$ and $I_{p}$ are also provided in Table 3 before and after 21 and 70 days of biodegradation. A slight decrease of the polydispersty index was also observed for both cast PHBV and C-PHBV/3C30B nanocomposite films.

This phenomenon was more pronounced for neat PHBV during the early stage of biodegradation (4-5 weeks), and this was confirmed by the results shown in Fig. 11, which reports the chain scission index $(S I)$ values, calculated after 21 and 70 days of biodegradation for cast PHBV and C-PHBV/3C30B nanocomposite samples according to $\mathrm{Eq}(7)$ :

$S I=\left[\overline{M_{n}}\left(\mathrm{t}_{0}\right) / \overline{M_{n}}(\mathrm{t})\right]-1$

Where $\overline{M_{n}}\left(t_{0}\right)$ and $\overline{M_{n}}(\mathrm{t})$ are the initial number average molecular weight and the number average molecular weight at a given time of biodegradation, respectively. Fig. 11 shows an increase in the SI value from 0.59 to 1.64 and from 0.22 to 1.13 after 21 and 70 days of biodegradation for cast PHBV and C-PHBV/3C30B, respectively, which confirms the occurrence of chain scission in PHBV matrix.

The molecular weight reduction during composting originates from two types of degradation mechanisms, i.e. hydrolytic and enzymatic. Hydrolytic degradation proceeds through water diffusion in the bulk of the material and can be responsible for a significant decrease in molecular weight. In contrast, enzymatic degradation is mainly localized at the surface of the material, degradation products being thus lost in the compost or by the washing, and hence non-detectable. It should be noticed that the diffusion of microorganisms through the bulk of the materials is

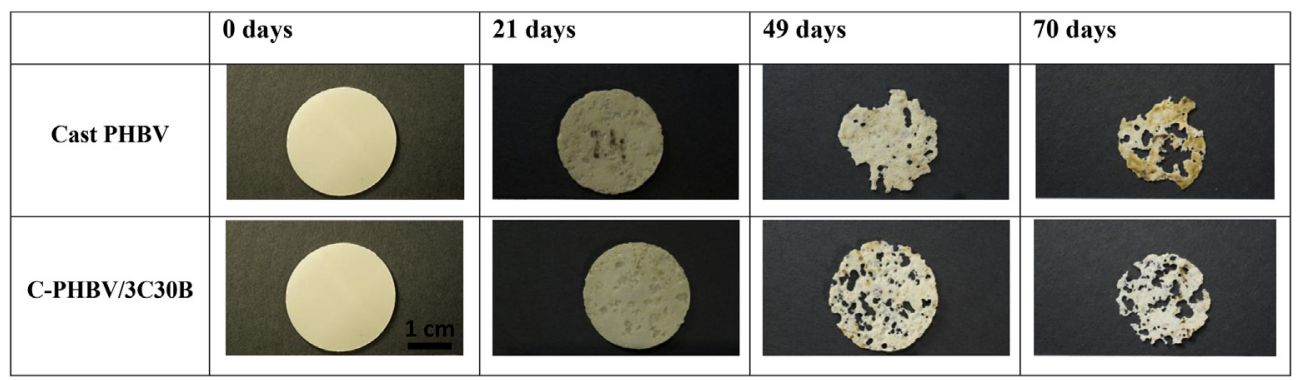

Fig. 8. Photomicrographs of cast PHBV and C-PHBV/3C30B nanocomposite films at different degradation times. 


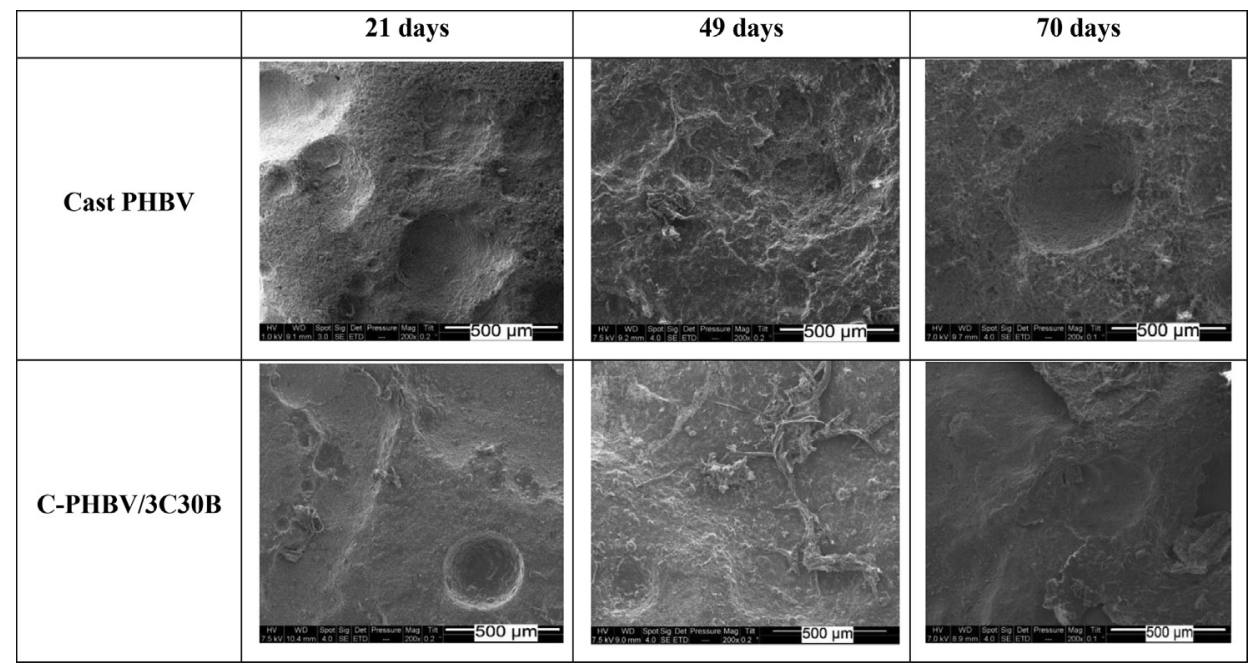

Fig. 9. SEM micrographs $(\times 200)$ of cast PHBV and C-PHBV/3C30B nanocomposite films at different degradation times.

made possible by the water. Therefore, enzymatic degradation could also occur in the bulk. Besides, the observation of molecular weight reduction upon biodegradation could also be conditioned by other structural features such as the degree of crystallinity of the polymer. Maiti et al. [8] reported a significant decrease of the molecular weight for PHB/OMMT nanocomposites after 4 weeks, while that of the neat PHB decreased slightly. The authors assumed that at early stage of biodegradation (up to 4-5 weeks), the limited reduction in $\overline{M_{w}}$ for PHB was due to its high degree of crystallinity, biodegradation taking place preferentially in the amorphous region of the polymer as assumed by Koyama and Doi [25]. The biodegradation of PHBV and PHBV/PHB blends in compost and seawater was investigated by Rutkowska et al. [26]. The authors found that the molecular weight of pure PHBV decreased slightly in both environments but no measurable changes in molecular weight were observed for the binary blends of PHBV and PHB. They concluded that PHBV degraded via enzymatic process with a slight influence of the hydrolytic process, which affected the bulk of the material. For the binary blend, the biodegradation took place only by enzymatic process via a surface erosion mechanism in both environments, the bulk of the material being unaffected. Similar results were found by Luo et al. [23]. The authors studied the

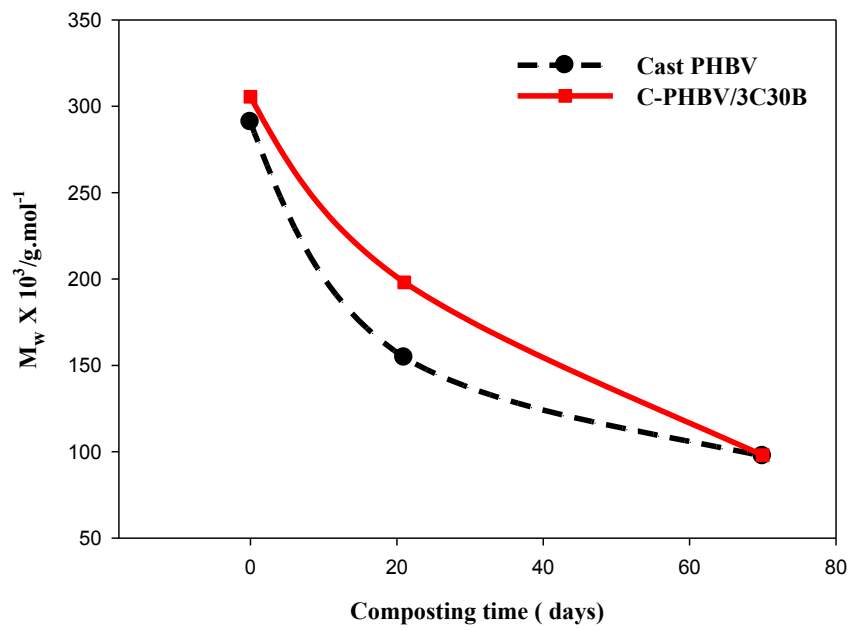

Fig. 10. Evolution of the molecular weight $\left(M_{w}\right)$ of cast PHBV and C-PHBV/C30B nanocomposite after 21 and 70 days of composting. biodegradation of PHBV films in composting conditions for 50 days. The data showed that the $\overline{M_{w}}$ of bulk PHBV measured by capillary viscometer did not change during composting. The authors explained that the biodegradation of the polymer only occurred via surface erosion mechanism, which should not affect the $\overline{M_{w}}$ of the remaining PHBV, small cleaved molecules present at the surface being lost in the composting medium or during washing.

In contrast, our results clearly show that the biodegradation in compost of cast PHBV and C-PHBV/3C30B nanocomposite occurred at the surface as well as in the bulk of the films, i.e. by combined enzymatic and hydrolytic degradation, since significant molecular weight reduction and chain scission (Figs. 10 and 11) were observed together with a strong erosion at the surface (Figs. 8 and 9). Even if the rate of molecular weight loss was more pronounced at early stage of biodegradation for PHBV films, the final molecular weights after 70 days of composting were similar (roughly $100000 \mathrm{~g} / \mathrm{mol}$ ) for both PHBV and nanocomposite films.

3.2.2.4. Microstructural changes. DSC analysis was used to investigate the changes in the crystalline structure of cast PHBV and C$\mathrm{PHBV} / 3 \mathrm{C} 30 \mathrm{~B}$ nanocomposite films during the composting process, and the results from the cooling and second heating scans are reported in Table 4. Prior to biodegradation in compost, a decrease in melting temperature $T_{m}$ and degree of cristallinity $X_{c}$ was observed for PHBV loaded with 3 wt. \% of C30B compared to cast PHBV. This could be the result of the PHBV degradation during processing as shown by SEC experiments, and possibly of the restricted polymer chain mobility in the presence of organoclays [27].

During biodegradation, the melting temperatures of cast PHBV and $\mathrm{C}-\mathrm{PHBV} / 3 \mathrm{C} 30 \mathrm{~B}$ nanocomposite obtained from the first heating scan remained constant. A slight decrease of the melting

Table 3

SEC results (weight-average molecular weight $\overline{M_{w}}$, number-average molecular weight $\overline{M_{n}}$ and polydispersity index $I_{P}$ ) of cast PHBV and C-PHBV/3C30B nanocomposite after 21 and 70 days of composting.

\begin{tabular}{lccl}
\hline Sample & $\overline{M_{w}}(\mathrm{~g} / \mathrm{mol})$ & $\overline{M_{n}}(\mathrm{~g} / \mathrm{mol})$ & $I_{P}$ \\
\hline Cast PHBV & 290862 & 112956 & 2.6 \\
Cast PHBV-21d & 154517 & 70806 & 2.2 \\
Cast PHBV-70d & 97422 & 42691 & 2.3 \\
C-PHBV/3C30B & 305510 & 94648 & 3.2 \\
C-PHBV/3C30B-21d & 198091 & 77413 & 2.6 \\
C-PHBV/3C30B-70d & 98024 & 44342 & 2.2 \\
\hline
\end{tabular}




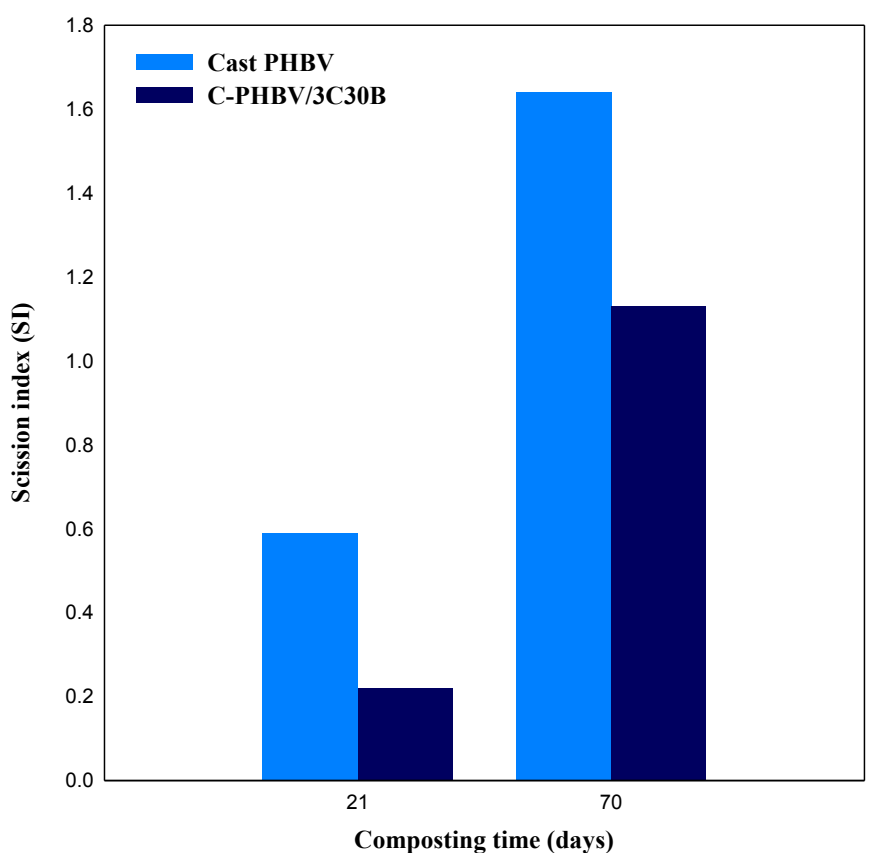

Fig. 11. Chain scission index (SI) of cast PHBV and C-PHBV/3C30B nanocomposite films.

temperature with increasing biodegradation time was observed from the second heating scan, indicating that the crystallization of degraded materials upon the cooling scan produces less perfect and/or thermally stable crystals that melt at lower temperature. As seen from SEC experiments (Figs. 10 and 11), the significant decrease in molecular weight of the samples should be responsible for this.

There were no significant changes in the crystallization temperature $\left(T_{c}\right)$ and the crystallinity index $\left(X_{c}\right)$ of the samples from the first heating scans, even after 70 days of incubation in composting conditions. Luo et al. [23] and Puglia et al. [10] observed same trends when studying the biodegradation in compost of PHBV and $\mathrm{PHB} /$ clays nanocomposites, respectively, and assumed that the degradation kinetics of crystalline and amorphous phases during composting were similar. However, the authors found that the sample degradation occurred through a layer by layer erosion from the surface to the bulk of the material, thus explaining the absence of crystallinity changes in the bulk. Degradation products were indeed leached in the compost or washed, and excluded from the DSC analysis. In the present work, it was clearly shown from SEC experiments that biodegradation also occurred in the bulk of the films. Our results thus suggest that the amorphous and crystalline phases in cast PHBV and C-PHBV/3C30B nanocomposite degraded at same rate with no change in the crystallinity index, even in the bulk of the material.

\subsubsection{Concluding remarks on the biodegradation of PHBV and its nanocomposites}

Summarizing, our results and those from literature clearly demonstrate that the presence of OMMT decreases the biodegradation rate of aliphatic polyesters whatever the biodegradation medium and conditions used. This phenomenon could be explained by the combination of several physico-chemical mechanisms: (i) the enhanced interactions of PHBV chains with dispersed layered silicate surfaces that restrict the molecular motion at the inorganic/organic interface [9] and was highlighted in the present work by the shift in the $\alpha$-transition temperature towards higher temperatures for nanocomposite films (Fig. 4); (ii) the limited diffusion of water and microorganisms into the bulk of the materials through the more tortuous pathway created by the dispersed clays (Figs. 2 and 3 ) that delayed the hydrolysis and the further biodegradation of polymer chains [18]; (iii) the quaternary ammonium salt present in organoclays that could act as a surfactant germicide [9] as well as a bacterial adsorber limiting then the microbial activity towards polymer chains. It should be noticed that the influence of OMMT was less marked for composting tests conducted at $58{ }^{\circ} \mathrm{C}$, molecular motions as well as water diffusion and hydrolysis of the chains being indeed enhanced at higher temperature. Moreover, we clearly showed, based on morphological observations and microstructural and macromolecular analysis by DSC and SEC, that biodegradation occurred at the surface as well as in the bulk of the films through enzymatic and hydrolytic processes, degrading amorphous and crystalline phases at the same rate.

\section{Conclusions}

PHBV/OMMT nanocomposite films were prepared by melt compounding and cast-film extrusion. The microstructural analysis indicated that the dispersion of OMMT within the PHBV matrix was relatively homogeneous and led to an intercalated structure, as revealed by WAXD and STEM. The SEC results indicated a degradation of the polymer matrix after processing which can be limited by the use of a masterbatch to produce nanocomposites. All the nanocomposite films exhibited enhanced thermo-mechanical properties and a shift of the $\alpha$-transition to higher temperatures, which attests for a good dispersion and affinity between the OMMT and the PHBV chains. The study of the biodegradation of C-PHBV/ C30B nanocomposite films in both environments, i.e. in aqueous solution and in laboratory-scale compost, indicates that the rate of biodegradation is directly dependent on the OMMT content. The

Table 4

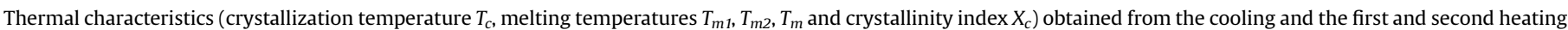
scans of cast PHBV and C-PHBV/3C30B nanocomposite after 7, 14, 21 and 70 days of composting.

\begin{tabular}{|c|c|c|c|c|c|c|}
\hline \multirow[t]{2}{*}{ Sample } & \multirow[t]{2}{*}{$T_{C}\left({ }^{\circ} \mathrm{C}\right)$} & \multicolumn{3}{|l|}{ 1st heating } & \multicolumn{2}{|l|}{ 2nd heating } \\
\hline & & $T_{m 1}\left({ }^{\circ} \mathrm{C}\right)$ & $T_{m 2}\left({ }^{\circ} \mathrm{C}\right)$ & $X_{c}(\%)$ & $T_{m}\left({ }^{\circ} \mathrm{C}\right)$ & $X_{c}(\%)$ \\
\hline Cast PHBV & $114.99 \pm 0.58$ & $169.51 \pm 0.44$ & $175.13 \pm 0.44$ & $58.46 \pm 1.27$ & $169.00 \pm 1.4$ & $66.67 \pm 0.03$ \\
\hline Cast PHBV-7d & $114.76 \pm 0.02$ & - & $172.65 \pm 0.47$ & $58.38 \pm 1.40$ & $168.09 \pm 0.63$ & $65.26 \pm 0.01$ \\
\hline Cast PHBV-14d & $114.86 \pm 0.26$ & - & $172.27 \pm 0.15$ & $57.18 \pm 0.06$ & $167.11 \pm 0.27$ & $64.03 \pm 0.06$ \\
\hline Cast PHBV-21d & $114.30 \pm 0.04$ & - & $172.94 \pm 0.08$ & $61.42 \pm 0.76$ & $166.50 \pm 0.65$ & $66.71 \pm 0.03$ \\
\hline Cast PHBV-70d & $113.86 \pm 0.20$ & - & $172.23 \pm 0.85$ & $59.78 \pm 0.15$ & $165.46 \pm 0.21$ & $64.83 \pm 0.01$ \\
\hline C-PHBV/3C30B & $119.87 \pm 0.04$ & $169.91 \pm 0.85$ & $173.60 \pm 0.87$ & $59.09 \pm 1.11$ & $165.01 \pm 0.04$ & $65.31 \pm 0.02$ \\
\hline C-PHBV/3C30B-7d & $119.08 \pm 0.18$ & $168.01 \pm 0.24$ & $172.90 \pm 0.04$ & $57.66 \pm 0.32$ & $166.13 \pm 0.14$ & $66.75 \pm 0.04$ \\
\hline C-PHBV/3C30B-14d & $119.35 \pm 0.16$ & $167.54 \pm 0.88$ & $173.08 \pm 0.60$ & $58.36 \pm 0.31$ & $163.69 \pm 1.28$ & $65.92 \pm 0.01$ \\
\hline C-PHBV/3С $30 \mathrm{~B}-21 \mathrm{~d}$ & $118.35 \pm 1.14$ & $168.44 \pm 0.90$ & $173.47 \pm 0.76$ & $60.43 \pm 0.60$ & $163.24 \pm 1.24$ & $68.30 \pm 0.01$ \\
\hline C-PHBV/3C30B-70d & $118.12 \pm 0.14$ & $166.80 \pm 0.84$ & $173.90 \pm 0.78$ & $61.84 \pm 0.45$ & $163.79 \pm 0.12$ & $66.46 \pm 0.02$ \\
\hline
\end{tabular}


nanocomposites samples indeed showed lower biodegradability than neat PHBV, due to several physico-chemical mechanisms, especially, a restricted molecular motion at the inorganic/organic interface and a barrier effect of the dispersed OMMT in the polymer matrix. The surface morphology of the films during the composting tests was characterized by the formation of pores and holes as a result of excessive degradation. As PHBV and C-PHBV/C30B nanocomposite films were degraded and lose mass, molecular weight was decreased and the chain scission index grows significantly. In the controlled biodegradation conditions used in this study, it can be concluded that the biodegradation mechanisms of PHBV are similar for its nanocomposites, and occur via surface erosion and random chain scissions in the bulk of the films. Besides, the degree of crystallinity of PHBV and its nanocomposites remained almost unchanged all over the composting, suggesting that the amorphous and crystalline phases of PHBV are equally disintegrated. Finally, the influence of OMMT was less marked in composting conditions conducted at $58{ }^{\circ} \mathrm{C}$, molecular motions as well as water diffusion and hydrolysis of the chains being indeed enhanced. Our results thus highlight the key role of the environmental conditions (humidity, temperature) on the waste management through composting of such biopolyester/OMMT nanocomposites.

\section{Acknowledgments}

The authors thank the Carnot M.I.N.E.S. Institute for its financial support (MB2 Project). I.K. gratefully acknowledges the Averroes program for financial support (Averroes 4), in the framework of the Erasmus Mundus European program.

\section{References}

[1] Khanna S, Srivastava AK, Khas H. Recent advances in microbial polyhydroxyalkanoates. Process Biochem 2005;40:2173-82.

[2] Amass W, Amass A, Tighe B. A review of biodegradable polymers: uses, current developments in the synthesis and characterization of biodegradable polyesters, blends of biodegradable polymers and recent advances in biodegradation studies. Polym Int 1998;47:89-144.

[3] Bordes P, Pollet E, Avérous L. Nano-biocomposites: biodegradable polyester/ nanoclay systems. Prog Polym Sci 2009;34:125-55.

[4] Bordes P, Hablot E, Pollet E, Avérous L. Effect of clay organomodifiers ondegradation of polyhydroxyalkanoates. Polym Degrad Stab 2009:94:789-96.

[5] Bordes P, Pollet E, Bourbigot S, Avérous L. Structure and properties of PHA/ Clay nano-biocomposites prepared by melt intercalation. Macromol Chem Phys 2008;209:1473-84.

[6] Chen GX, Hao GJ, Guo TY, Song MD, Zhang BH. Structure and mechanical properties of poly(3-hydroxybutyrate-co-3-hydroxyvalerate) (PHBV)/clay nanocomposites. J Mater Sci Lett 2002;21:1587-9.

[7] Pandey JK, Reddy KR, Kumar AP, Singh RP. An overview on the degradability of polymer nanocomposites. Polym Degrad Stab 2005;88:234-50.
[8] Maiti P, Batt Carl A, Giannelis EP. New biodegradable polyhydroxybutyrate layered silicate nanocomposites. Biomacromolecules 2007;8:3393-400.

[9] Wang S, Song C, Chen G, Guo T, Liu J, Zhang B, et al. Characteristics and biodegradation properties of poly(3-hydroxybutyrate-co-3-hydroxyvalerate) organophilicmontmorillonite (PHBV/OMMT) nanocomposite. Polym Degrad Stab 2005;87:69-76.

[10] Puglia D, Fortunati E, D'Amico DA, Manfred LB, Cyras VP, Kenny JM. Influence of organically modified clays on the properties and disintegrability in compost of solution cast poly(3-hydroxybutyrate) films. Polym Degrad Stab 2014;99: 127-35.

[11] Barham PJ, Keller A, Otun EL, Holmes PA. Crystallization and morphology of a bacterial thermoplastic: poly-3-hydroxybutyrate. J Mater Sci 1984;19: 2781-94.

[12] EN ISO 14851. Determination of the ultimate aerobic biodegradability of plastic materials in an aqueous medium-method by measuring the oxygen demand in a closed respirometer. 2004.

[13] EN ISO 20200. determination of the degree of disintegration of plastic materials under simulated composting conditions in a laboratory-scale test. 2004.

[14] Choi WM, Kim TW, Park OO, Chang YK, Lee JW. Preparation and characterization of poly(hydroxybutyrate-co-hydroxyvalerate)-organoclaynanocomposites. J Appl Polym Sci 2003;90:525-9.

[15] Renstad R, Karlsson S, Albertsson AC. Influence of processing parameters on the molecular weight and mechanical properties of poly(3-hydroxybutyrateco-3-hydroxyvalerate). Polym Degrad Stab 1997;57:331-8.

[16] Cabedo L, Plackett D, Giménez E, Lagaron JM. Studying the degradation of polyhydroxybutyrate-co-valerate during processing with clay-based nanofillers. J Appl Polym Sci 2009;112:3669-76.

[17] Hablot E, Bordes P, Pollet E, Avérous L. Thermal and thermo-mechanical degradation of poly(3-hydroxybutyrate)-based multiphase systems. Polym Degrad Stab 2008;93:413-21.

[18] Lee SR, Park HM, Lim H, Kang T, Li X, Cho WL. Microstructure, tensile properties, and biodegradability of aliphatic polyester/clay nanocomposites. Polymer 2002;43:2495-500.

[19] Mustin M. Le Compost, Gestion de la Matière Organique. Paris: F. Dubusceds; 1987.

[20] EN ISO 16929. Plastics-determination of the degree of disintegration of plastic materials under defined composting conditions in a pilot-scale test. 2013.

[21] Lotto NT, Calil MR, Guedes CGF, Rosa DS. The effect of temperature on the biodegradation test. Mater Sci Eng 2004;C24:659-62.

[22] Weng YX, Wang Y, Wang XL, Wang YZ. Biodegradation behavior of PHBV films in a pilot-scale composting condition. Polym Test 2010;29:579-87.

[23] Luo S, Netravali AN. A study of physical and mechanical properties of poly(hydroxybutyrate-co-hydroxyvalerate) during composting. Polym Degrad Stab 2003;80:59-66.

[24] Phua YJ, Lau NS, Sudesh K, Chow WS, Mohd I ZA. Biodegradability studies of poly (butylenes succinate)/organo-montmorillonitenanocomposites under controlled compost soil conditions: effect of clay loading and compatibiliser. Polym Degrad Stab 2012;97:1345-54.

[25] Koyama N, Doi Y. Effects of solid-state structure on the enzymic degradability of bacterial poly(hydroxyalkanoic acids). Macromolecules 1997:30:826-32.

[26] Rulkowska M, Krasowska K, Heimowska A, Adamus G, Sobota M, Musiol M, et al. Environmental degradation of blend atactic poly[(R,S)-3hydroxybutyrate] with natural PHBV in baltic sea water and compost with activated sludge. J Polym Environ 2008;16:183-91.

[27] Botana A, Mollo M, Eisenberg P, Sanchez RMT. Effect of modified montmorillonite on biodegradable PHB nanocomposites. Appl Clay Sci 2010;47: 263-70. 